\title{
Automatic EB Billing Using GSM Technique
}

\author{
R.Gunasekaran \\ Assistant Professor, Electrical and Electronics \\ Engineering, Excel College of Engineering\& \\ Technology, Komarapalayam ,India \\ gunaped@gmail.com
}

\author{
Dr. C.Karthikeyan \\ Associate Professor, Electrical and Electronics \\ Engineering, K.S.Rangasamy College of \\ Engineering, KSR Kalvi Nagar, Tiruchengode \\ Namakkal (Dist.), Tamil Nadu,India \\ ckarthykeya@gmail.com
}

\author{
R.Kavin \\ Assistant Professor, Electrical and Electronics Engineering \\ Excel College of Engineering\& Technology, Komarapalayam \\ kavin882@gmail.com
}

\begin{abstract}
Now a day the energy meter monitoring and taking the readings needs lot of manual power.It is also an urgent problem that the household wants to solve it because, the accuracy and real time of meter data copy affects the power system information level, management decisions and economic benefits. We overload electrical circuits it could cause a fire and load demand. The home appliances, which consume more power, cause an increase in the payment of excessive bills. Automatic Meter Reading (AMR) technologies in Electrical Utilities (EUs) have been exploiting their own infrastructure to bill their customers in an efficient and economical way. This project is having the facility of getting the meter reading and overload indication at any time by the customer mobile and EB office. We are using the PIC microcontroller for the efficient energy meter monitoring system. This system is connected with the energy meter with load. The IR receiver is used to count the reading of the energy meter. The value of the IR receiver will be given to the microcontroller. The EB bill and overload occurred message would be send to consumer mobile number and EB office mobile number by using GSM modem. The status will be displayed in LCD, which is interfaced with the microcontroller.
\end{abstract}

Key Words: Automatic Meter Reading (AMR), Electrical Utilities (EUs), PIC microcontroller, GSM modem.

\section{INTRODUCTION}

In recent years, energy meter reading is manually taken and sends to the EB office and the user, which is the main problem. It is rectified by using GSM technology. It can be used for commercial applications. It can be developed as a primary meter, sub meter or used for other electric metering applications such as demand reduction.

Its open system design and easy worldwide development leads to output with real time data based on accurate measurement .This electric meter is designed to meet requirements for data on demand from multiple users. Traditional meters focus only on single user applications at fixed time intervals.

It is the right solution in today's complex energy market combining low cost, high accuracy, minimum cost of communications with real time data access and reporting. This sophisticated GSM enabled meter combines elements of simplicity, is highly functional and reduces overall ownership costs.

Automatic Meter Reading (AMR) technology in Electrical Utilities (EUs) have been exploiting their own infrastructure to bill their customers in an efficient and economical way and facility to getting the meter reading and overload indication at any time by customer mobile number and EB office.

Since most facilities already have an existing network, the cost of communication is virtually less. This advanced meter provides peak demand $(\mathrm{kW})$ with a date and time stamp informing when the peak demand occurred.

It also has the capability to periodically record and store interval data usage (load profile) based on a user defined interval. This functionality helps identify where, when and how much energy was 
consumed. It can also store value of energy consumption by Time-Of-Use (TOU). This allows end users to identify how much energy was consumed during different periods of the day.

Some of these features are listed below,

- Higher speed

- Improved load profile

- Automatic billing

- Real time energy cost

- Load management

- Alarm warning at overload condition

\subsection{Research Problem}

Now a day the energy meter monitoring and taking the readings needs lot of manual power. It consumes wastage of energy and it is a time consuming process. Reading values are not accurate. We overload the circuits it could cause a fire and load demand. The number of electricity consumers is increasing in great extent. It became a hard task in handling and maintaining the power as per the growing requirements. If the consumer is not available, the billing process will be pending and human operator again needs to revisit.

Going to each and every consumer's house and generating the bill is a laborious task and requires lot of time. It becomes very difficult especially in rainy season. If any consumer did not pay the bill, the operator needs to go to their houses to disconnect the power supply. These processes are time consuming and difficult to handle. Moreover, the manual operator cannot find the un-authorized connections or malpractices carried out by the consumer to reduce or stop the meter reading/power supply.

The human error can open an opportunity for corruption done by the human meter reader. So the problem which arises in the billing system can become inaccurate and inefficient.

\subsection{Objective of the Thesis}

The main objective of this thesis is to greatly reduce the manpower, save time and to operate efficiently without any human interference by means of automatic EB billing and overload indication using the microcontroller chip with a new approach for data security and transmission of data using GSM technology.

\subsection{Scope of Work}

Better management of total energy usage and get details about the amount and timing of your energy use, so we can adjust accordingly and save money. Advanced meter data can be used to compare costs between competing utilities and to arrange for bulk-rate purchasing. Identify and implement operational strategies to control load factor, peak load requirements and reduce energy waste and understand the consumption patterns.

\subsection{Methodology}

The following methodology has been adopted in order to carry out the Research work:

- The complete control is done through microcontroller (PIC16F877A) with help of coding.

- This system is connected with the energy meter with load.

- The IR receiver is used to count the reading of the energy meter. The value of the IR receiver will be given to the microcontroller.

- At every 2 months the total bill amount will be transmitted to the EB section and the user mobile.

- If a user uses more than the fixed range of current means automatically an alarm will on and after some minutes the main supply will be switched off using relay circuit.

- The status will be displayed in LCD which is interfaced with the microcontroller.

International Journal of Research Studies in Electrical and Electronics Engineering (IJRSEEE) Page 7 


\section{BLOCK DIAGRAM}

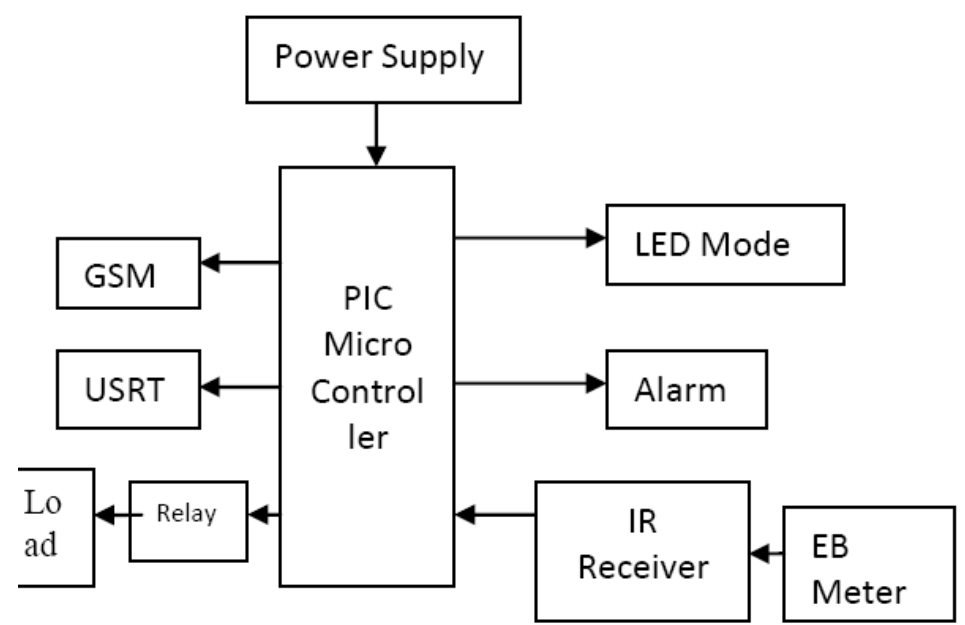

Fig1. Block diagram of home section

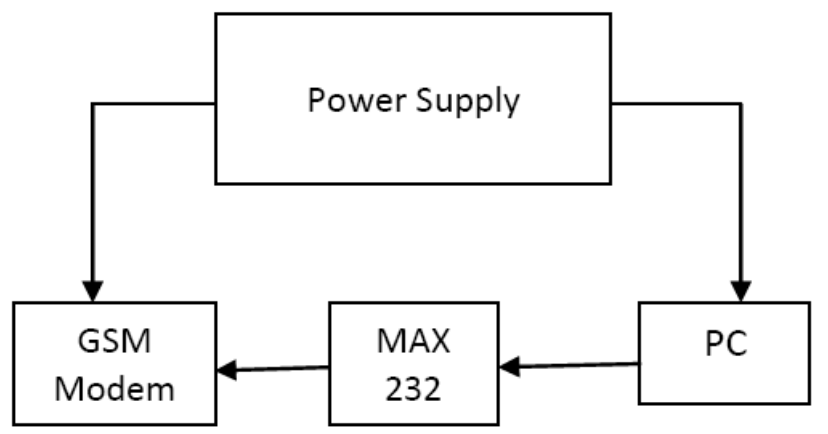

Fig2. Block diagram of EB section

\subsection{Block Diagram Explanation}

Here the input given to the project is $230 \mathrm{~V}$ AC and controller get DC supply from rectifier circuit. The microcontroller is connected with the energy meter with load. The IR receiver is used to count the reading of the energy meter. The value of the IR receiver will be given to the microcontroller. At every 2 months the total bill amount will be transmitted to the EB section and the user mobile. If a user uses more than the fixed range of current means automatically an alarm will on and after some minutes the main supply will be switched off using relay circuit. The status will be displayed in LCD which is interfaced with the microcontroller.

\section{HARDWARE DESCRIPTION}

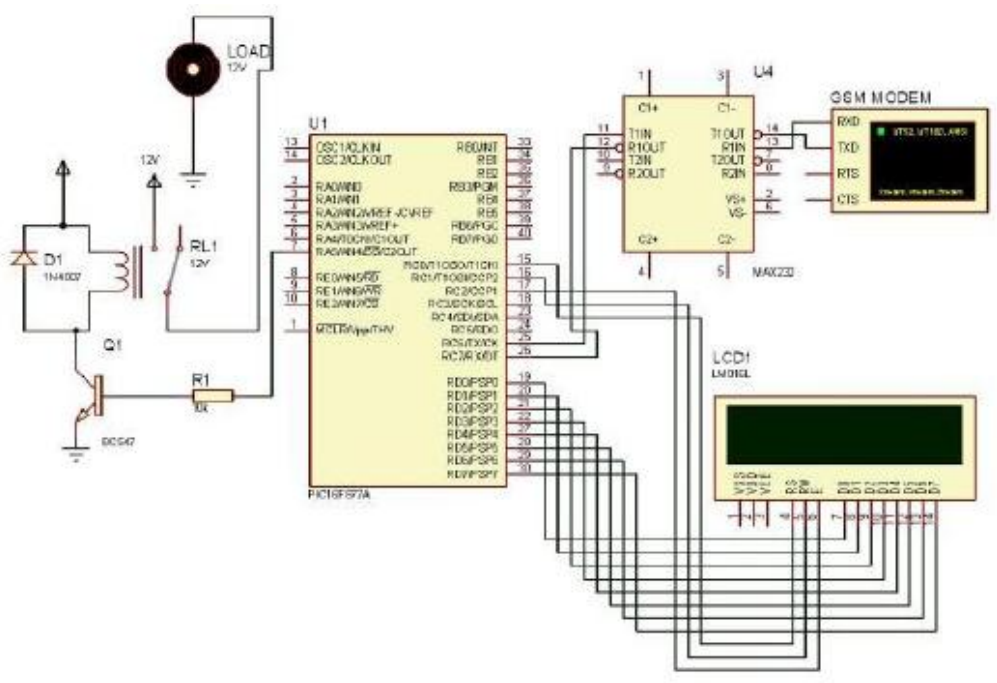

Fig3. Circuit diagram of hardware in home section 


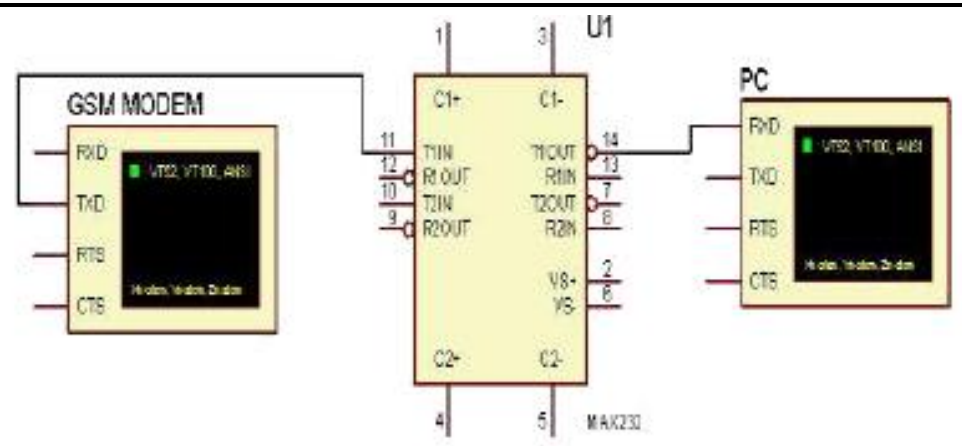

Fig4. Circuit diagram of hardware in EB section

\subsection{Circuit Diagram Expiation}

In this overload indication and automatic EB billing in energy meter project we are employed an electronic energy meter for calculating the electrical power consumption of the users.

The single phase, $230 \mathrm{~V}, 50 \mathrm{HZ}$ AC supply is directly connected with the load section through the energy meter. This single phase $230 \mathrm{~V}$ AC supply is step downed to $12 \mathrm{~V}$ AC by $12-0-12 \mathrm{~V}$ center tapped transformer for electronic section. For the microcontroller section $+5 \mathrm{~V}$ DC supply is needed. For this purpose $12 \mathrm{~V} \mathrm{AC}$ supply is rectified using diode bridge rectifier circuit. In this bridge rectifier there are four numbers of diodes(IC IN4007) are used.

The output DC supply from the bridge rectifier circuit is regulated by the voltage regulator IC7805 to maintain constant $+5 \mathrm{~V}$ DC supply. There are two number of capacitors are used for the filtering purpose.

This +5V DC supply is given to the Vin pin of the PIC16F877A microcontroller which controls the GSM modem circuit, buzzer circuit, LCD circuit and relay operation.

GSM modem is interfaced by the PIC microcontroller through MAX232 cable using IC MAX232EPE. +12V DC supply is given to GSM modem. In this, a SIM card is used for data transfer purpose. There are two number of GSM modems used one is for home section and another one is in EB section both acts like a transceiver.

Other peripherals such as LCD, buzzer and relay circuit are directly controlled by the microcontroller. There is a reset button by which we can reset the microcontroller.

In the EB section, the single phase, $230 \mathrm{~V}$, AC supply is step downed to $12 \mathrm{~V}$ AC supply by $12-0-12 \mathrm{~V}$ centre tapped transformer and it is rectified by the bridge rectifier and given to the GSM modem.

The GSM modem is connected to the computer through MAX232 cable. To send and receive the data from the EB section to home section, hyperactive terminal application is used.

\section{Hardware Output Home Section}

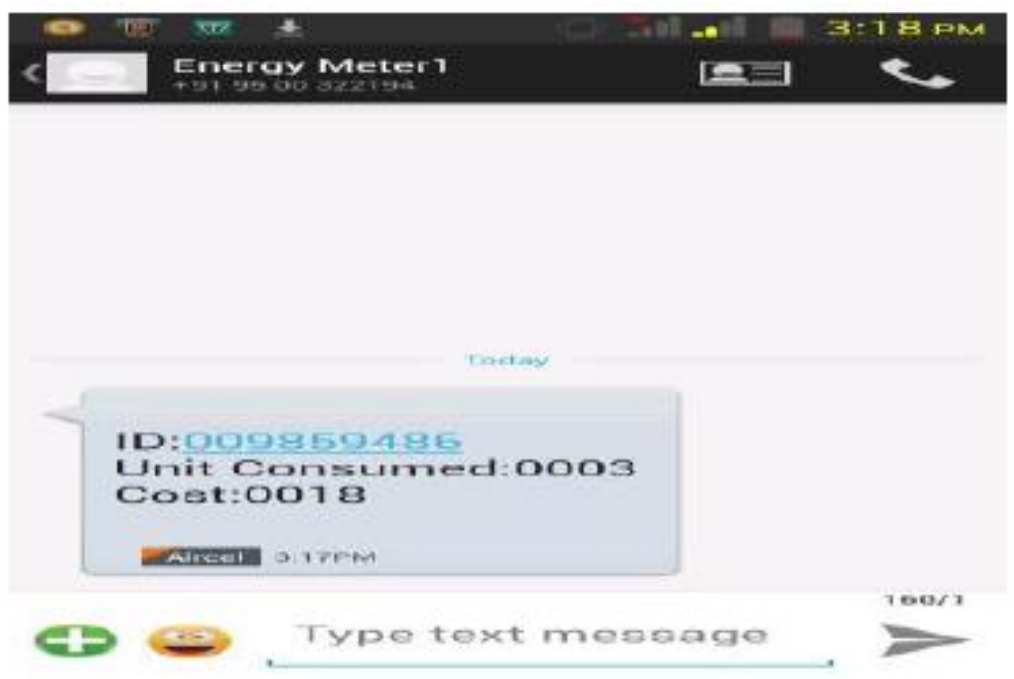

Fig5. EB Billing Output Value 


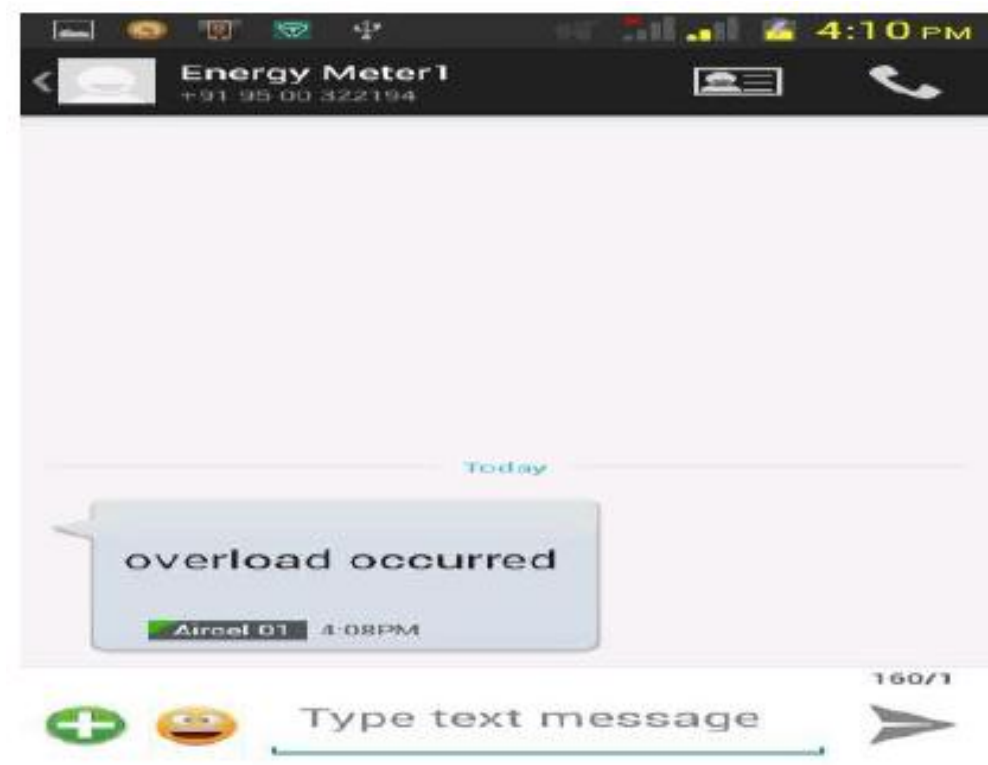

Fig6. Overload Indication Output

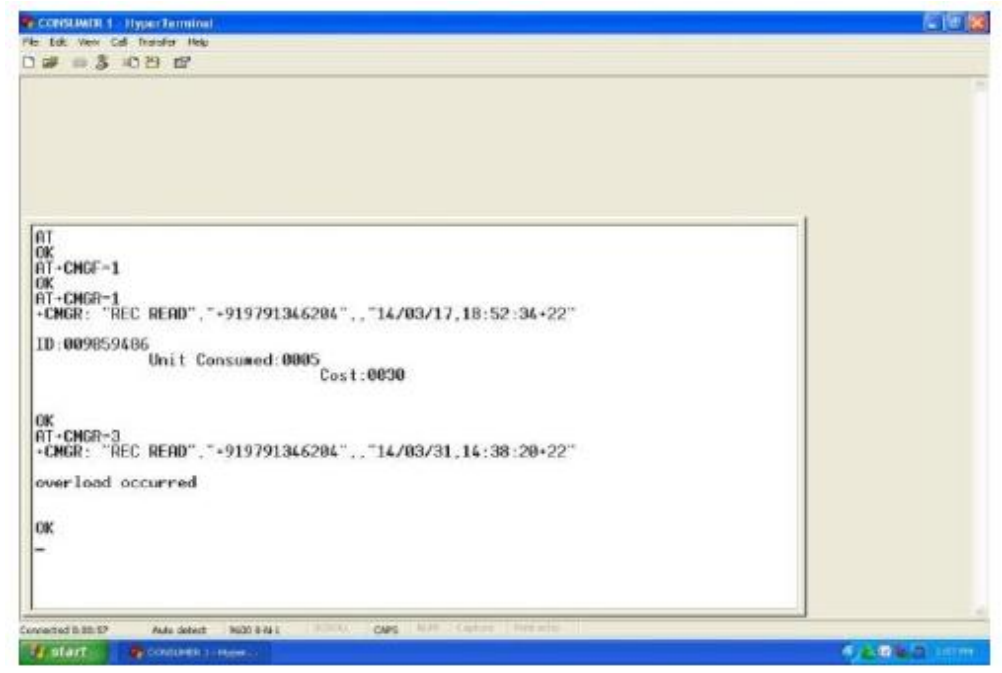

Fig7. EB Billing and Overload Indication Output Value in EB Section

\section{HaRdWARE KIT}

Overload Indication and Automatic EB Billing Using GSM Technique

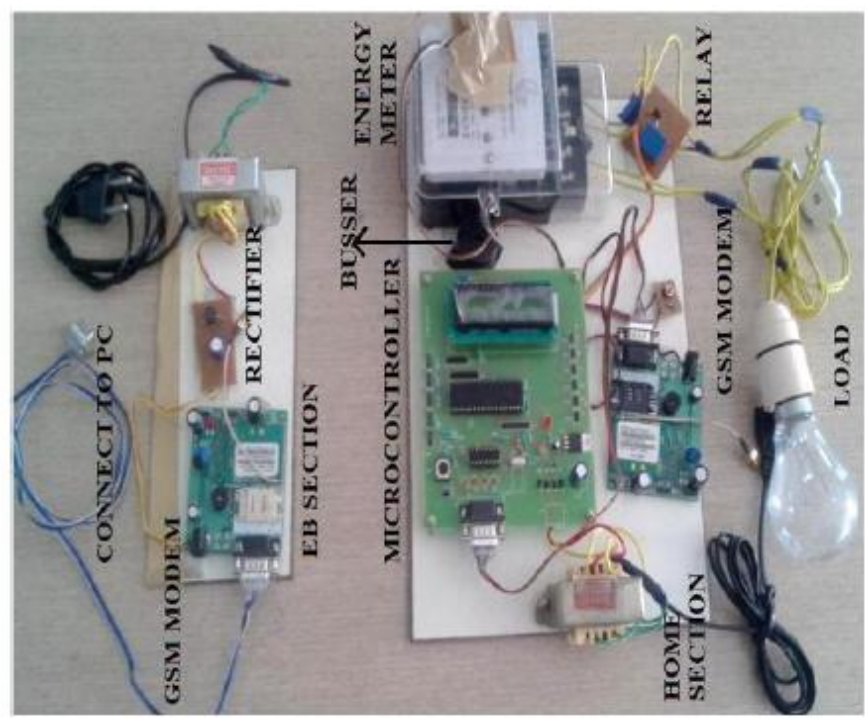

Fig8. Hardware Circuit Diagram 


\section{CONClusion}

Various electronic meters have been developed and are still being developed. However the use of GSM in this particular system provides numerous advantages over methods that have been previously used. Data transmission is charged at standard SMS rates, thus the charges are not based on the duration of data transmission. The cost efficient transmission of readings ensures that power consumption values can be transmitted more frequently to a remote station. The implications of being able to transmit readings more often are that energy utilities will be able to generate timely bills, better understand energy demand patterns, manage meter failures more efficiently and manage fraud better. By performing overload indication and tripping the supply we can restrict the power utilization beyond the allocated ratings for customers and also voltage fluctuation problem to the neighbouring customers can be minimized.

\section{FUTURE ENHANCEMENT}

In our approach, we designed a system with IR sensor and GSM technology. Instead of this we can use SPI metering IC which will provide more parameters. By using three phases IC MCP3909 we can extend to the three phase supply and also advanced technologies such as WIFI, ZIG-BEE can be used instead of GSM technology.

\section{REFERENCES}

[1] Bharath P, Ananth N, Vijetha S, Jyothi Prakash K. V. "Wireless automated digital Energy Meter", ICSET 2008.

[2] Bharat Kulkarni "GSM Based Automatic Meter Reading System Using ARM Controller "International Journal of Emerging Technology and Advanced Engineering Website, Volume 2, Issue 5, May 2012

[3] H.G.RodneyTan,C.H. Lee,V.H.Mok, "Automatic power meter reading system using GSM network", The 8 Conference (IPEC 2007). International Power Engineering.

[4] Li Kaicheng, Liu Jianfeng, Yue Congyuan, Zhang Ming. "Remote power management and meter-reading system based on ARM microprocessor",PrecisionElectromagnetic Measurements Digest, 2008. CPEM 2008. Conference on Digital Object Identifier.

[5] M.P Praveen, "KSEB to introduce SMS-based fault maintenance system", The Hindu News on 26/06/2011, http://www.hindu.com.

[6] P.K. Lee and L.L. Lai, Fieee, "A practical approach to wireless GPRS on-line power quality monitoring system", Power Engineering Society General Meeting,2007.

[7] Rahul Ganesh Sarangle, Prof. Dr. UdaypanditKhot, Prof. JayanModi" Gsm Based Power Meter Reading And Control System "Mr. Rahul Ganesh Sarangle, Prof. Dr.UdayPaniKhot, Prof JayenModi International Journal of Engineering Research and Applications (IJERA)4, June July 2012.

[8] Subhashis Maitra, "Embedded Energy Meter- A new concept to measure the energy consumed by a consumer and to pay the bill", Power System Technology and IEEE Power India Conference, 2008.

[9] S.Arun, Dr.Sidappa "Design and Implementation of Automatic Meter Reading System Using GSM, ZIGBEE through GPRS". International Journal of Advanced Research in Computer Science and Software Engineering Research Paper. Volume 2, Issue 5, May 2013.

[10] T El-Djazairy, B J Beggs and I F Stewart, " Investigation of the use of the Global System for Mobile Communications (GSM) network for metering and load management telemetry", Electricity Distribution. Part 1: Contributions. CIRED. 14th International Conference and Exhibition on (IEE Conf. Publ. No. 438).

[11] Tariq Jamil, "Design and Implementation of a Wireless Automatic Meter Reading System" WCE 2008, July 2-4, 2008, London, U.K. IAENG Processing of the World Congress on Engineering 2008 Vol I. July 2-4, 2008, London

[12] Vivek Kumar Sehgal,Nitesh Panda, Nipun Rai Handa, "Electronic Energy Meter with instant billing",UKSim Fourth European Modelling Symposium on Computer Modelling and Simulation.

[13] Yujun Bao and Xiaoyan Jiang, "Design of electric Energy Meter for long-distance data information transfers which based upon GPRS", ISA 2009.

International Journal of Research Studies in Electrical and Electronics Engineering (IJRSEEE) Page | 11 


\section{AUTHORS BIOGRAPHY}

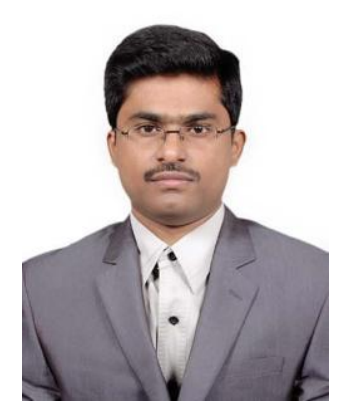

R.Gunasekaran was born in Erode in the year of 1981. He had his under graduation (B.E. - EEE) in the year of 2003 from Kongu Engineering College, Perundurai and post graduated M.E (Power Electronics \& Drives) at KSR College of technology in the year of 2010. He will current doing Ph.D., (parttime) Anna university, Chennai at 2015 onwards. He is currently working as Assistant professor in the department of EEE at Excel College of Engineering and Technology, komarapalayam from June 2015. His research interest involves in power electronics, Renewable energy.

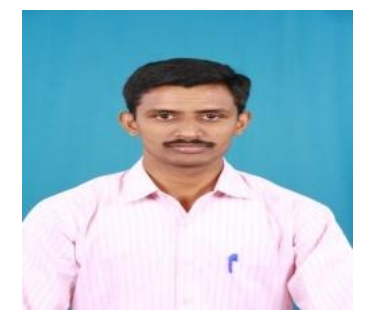

R.Kavin was born at Erode in the year of 1985. He completed his under graduation B.E (EEE) at KSR College of technology in the year of 2007. He did his M.E (Power Electronics \& Drives) at Sri Venkateswara college of Engineering in the year of 2010, Sriperumpudhur, Chennai. Currently he is working as Assistant Professor in the Dept of EEE at Excel College of Engineering \& Technology, Namakkal. His research area includes Power Electronics, Control systems. 